\title{
Para repensar la propiedad privada
}

\author{
Claudio E. Guiñazú ${ }^{1}$ \\ Universidad Nacional de Córdoba - Argentina
}

Revista Derechos en Acción ISSN 2525-1678/ e-ISSN 2525-1686

Año 5/NNo 16 Invierno 2020 (21 junio a 20 septiembre), 205-211

DOl: https://doi.org/10.24215/25251678e420

Recibido: 01/04/2020

Aprobado: 01/08/2020

Si admitimos que es posible reconstruir un concepto laico de "lo sagrado" seguramente muchos no dudarían en adjetivar de ese modo a la propiedad, en rigor, al derecho de propiedad privada $^{2}$. Derecho estrechamente vinculado a la concepción liberal e individualista del sujeto acuñada en la modernidad, donde la propiedad se configuró como el presupuesto para una existencia plena y autónoma. Así, la condición de "propietario" aseguraba efectivamente al sujeto la no dependencia personal y la posibilidad de desarrollar sus capacidades e iniciativas. Se entendía que a partir de la propiedad privada el hombre deviene propietario y podía acceder a la propiedad de sí, con la consiguiente posibilidad de autodeterminarse, convirtiéndose en ciudadano ${ }^{3}$.

1 Profesor de Derecho Constitucional, Universidad Nacional de Córdoba. Miembro del Grupo de Investigación en Derechos Sociales (GIDES), CIJS-UNC. (ORCID https://orcid. org/0000-0002-4326-2428).

2 Ya en 1766 Beccaria se refería a la "sagrada propiedad de los bienes", sin perjuicio de afirmar que ni esta última ni la seguridad del comercio podrían justificar la privación de libertad de un deudor "inocente fallido". Cfr. BECCARIA, Cesare, Tratado de los delitos y de las penas, trad. Juan Antonio de las Casas, Universidad Carlos III de Madrid, Historia del derecho, 32, Madrid, 2015, p. 73.

3 Mediante su teoría de la apropiación Locke desarrolló explícitamente esta concepción del individuo, cuando sostenía que "...es evidente que aunque las cosas de la naturaleza 
Castel tildó a esta concepción de ingenua y ahistórica, entendiendo que la propiedad privada es en verdad un "soporte" para la existencia del individuo ${ }^{4}$. Parece entonces que cualquier propuesta para repensar la propiedad privada en las sociedades actuales debe venir acompañada -para su solidez- por una concepción del individuo que le sirva de respaldo, sustitutiva de la pergeñada en la modernidad.

La configuración moderna de la propiedad privada trasciende el interés económico individual y tiene proyecciones políticas, ocupando un lugar emblemático en las tres acepciones de la dicotomía entre las esferas de lo público y lo privado, en su delimitación y articulaciones, y en la consecuente distinción entre derecho público y privado ${ }^{5}$. Como se indicó, la propiedad

hayan sido dadas en común, el hombre (como dueño de sí mismo y propietario de su persona y de las acciones o trabajo aplicado a aquélla) poseía en sí mismo el gran fundamento de la propiedad...". LOCKE, John, Ensayo sobre el gobierno civil, trad. de Sergio Albano, Ed. Gradifco, Buenos Aires, 2005, § 44, p. 57.

4 “He dicho, efectivamente, que tal concepción me parecía ingenua en el sentido que era substancialista. Tratándose del individuo, ¿qué es, en efecto, lo que escuchamos constantemente en el discurso liberal o neoliberal? Que hay individuos que no piden otra cosa que expresarse como tales, para desarrollar sus capacidades e iniciativas, bloqueadas por constricciones de tipo estatal o burocrático. Será suficiente entonces liberar al individuo de esos obstáculos para que adquiera su plenitud y se vuelva entonces más productivo en el plano económico, pero también para que se realice en el plano personal. Es concebir al individuo como si estuviera dado de una vez por todas, sin depender de las condiciones sociales e históricas de existencia. En relación a -y contra- esta posición, se debe formular la hipótesis de que un individuo no existe como una substancia, y que para existir como individuo es necesario tener soportes, y por lo tanto debemos interrogarnos sobre lo que hay 'detrás' del individuo para permitirle existir como tal. Podemos explicitar esta hipótesis en dos direcciones. Por una parte, esos soportes pueden ser de diversos tipos; por otra parte, y de manera complementaria, dichos soportes, que sirven de ámbito al individuo, han variado históricamente... Locke es uno de los primeros -si no el primero- en desarrollar una teoría del individuo moderno a partir de la toma de conciencia de la necesidad, para este individuo, de apoyarse sobre el zócalo de la propiedad privada para existir". De los comentarios de Robert Castel en las conversaciones con Claudine Haroche sobre la construcción del individuo moderno. CASTEL, Robert y HAROCHE, Claudine, Propiedad privada, propiedad social, propiedad de sí mismo, trad. de Alejandro Moreira, Ed. Homo Sapiens, Rosario, 2003, p. 12.

5 Sobre las tres acepciones de la dicotomía público/privado, ver RABOTNIKOF, Nora, "Lo público hoy: lugares, lógicas y expectativas", en Iconos, №32, Flacso-Ecuador, Quito, Sept. 2008, pp. 37-48. 
privada ha operado además como presupuesto o soporte para adquirir el status político de ciudadano, y conllevaba el poder de la autoridad doméstica del hombre sobre la esfera privada (familiar), y las personas a él sometidas, como mujeres, niños, ancianos, y otras personas consideradas dependientes ${ }^{6}$, cuya supervivencia resulta gobernada por la necesidad. Para éstas últimas vivir en la esfera privada equivalía a privación ${ }^{7}$. Esta dimensión de la propiedad está profundamente arraigada y se remonta hasta el derecho romano, constituyendo un "pliegue" que se ha mantenido hasta la actualidad, y se encuentra presente en la distinción entre las esferas dicotómicas entre lo público y lo privado, más allá de las transformaciones que ha experimentado.

Tal vez debido a estas profundas implicaciones políticas, económicas y culturales no abundan los autores que se han

6 “El espacio privado, en oposición al espacio público, era, en la tradición del siglo XIX, aquel en el cual el individuo aceptaba que su libertad fuera limitada por reglas de organización social de carácter prepolítico. Era una zona franca de la democracia, en la que se ejercían lisa y llanamente las reglas de la autoridad paterna. El espacio público, al contrario, era el lugar de la referencia común, y por consiguiente, de los principios. Por eso mismo era el lugar de la política, es decir aquél donde se definían las reglas sociales destinadas a transformar el mundo y, sustrayendo al individuo del reino de la necesidad, hacerlo advenir como ciudadano. Más: el individuo podía emanciparse tanto mejor afuera por estar sólidamente anclado en la tradición dentro del espacio doméstico; el segundo servía de palanca al primero. Semejante construcción, sin embargo, sólo funcionaba a costa del sometimiento de las mujeres. En cierta manera, la excepción a la ciudadanía impuesta a la familia, y por lo tanto a las mujeres, fue el precio pagado por la emancipación del individuo masculino: el hecho de que la estructura familiar no fuera cuestionada hizo que funcionara el pacto republicano, se acelerara la laicización de la sociedad, se desarrollara la sindicalización; en suma, que el trabajo de la democracia franqueara la etapa que conocemos". FITOUSSI, Jean-Paul y ROSANVALLON, Pierre, La nueva era de las desigualdades, trad. de Horacio Pons, Ed. Manantial, Buenos Aires, 2003, p. 48.

7 Cfr. ARENDT, Hannah, La condición humana, trad. de Ramón Gil Novales, Ed. Paidós, Buenos Aires, 2012, p. 67.

8 Es decir "una especie de sedimentación que pese a las transformaciones históricas que se han suscitado, se mantiene como un remanente de la organización política". CHAPARRO MEDINA, Paola y BUSTOS GARCÍA, Brenda A., "EI dispositivo de excepción en las sociedades contemporáneas: apuntes para reflexionar en torno al cuerpo femenino", en RELACES, № 26 , Año 10, p. 37. Disponible en: www.relaces.com.ar (accedido el 03/03/20). 
atrevido a desafiar el "dogma" de la propiedad privada, según su lectura liberal naturalizada, ya sea reflexionando sobre sus fundamentos, ya sea proponiendo otros principios para su regulación jurídica y legal.

En 1916 Russell cuestionó "la religión de los bienes materiales" cuando la ambición va más allá de las necesidades finitas para la subsistencia humana. Proponía entonces una distribución más justa de la propiedad de la tierra en Inglaterra, a la que calificaba de indefendible, entendiendo que la modificación de su regulación legal era posible en muchos aspectos "que la familiaridad nos hace mirar como naturales e inevitables". Distinguía cuatro orígenes de los derechos reconocidos por la ley a la propiedad privada: 1 . derecho del hombre a lo que él mismo ha hecho; 2. derecho al interés sobre el capital que se ha prestado; 3. propiedad de la tierra; y 4. herencia; sosteniendo que conformaban un crescendo de respetabilidad, donde la forma más respetable de riqueza, cualquiera sea su forma, es la heredada ${ }^{10}$.

En el mismo decenio Duguit propuso el concepto de "función social de la propiedad", probablemente uno de los más influyentes en el siglo XX, sosteniendo que la propiedad no es un derecho sino una función social ${ }^{11}$. En esta concepción la propiedad tiene tanto límites internos como externos, a diferencia

9 RUSSELL, Bertrand, Principios de reconstrucción social, trad. de E. Torralva Beci, Ed. Espasa-Calpe, Madrid, 1978, p. 104.

10 Ídem. Sostenía incluso que "la propiedad privada de la tierra no tiene justificación, no siendo la histórica de la potencia de la espada... La tierra se hizo propiedad de los que la habían conquistado y se permitió a los siervos que pagaran rentas en vez de servicios. No hay justificación para la propiedad privada de la tierra excepto en la necesidad histórica de llegar a una conciliación con los ladrones, que de otro modo no se hubieran sometido a la ley. Esta necesidad se produjo en Europa hace varios siglos... Es un ejemplo singular de la inercia humana que los hombres hayan continuado hasta ahora soportando la tiranía y la violencia que les puede infligir una pequeña minoría por el hecho de poseer la tierra. No resulta para la colectividad ninguna especie o género de bien de la propiedad privada de la tierra". Op. cit., p. 106.

11 FOSTER, Sheila y BONILLA MALDONADO, Daniel, "Introducción. La función social de la propiedad en perspectiva comparada" en BONILLA MALDONADO, Daniel (coord.) La función social de la propiedad, trad. de Carlos Morales, Eudeba, Buenos Aires, 2013, p. 13. 
del derecho de propiedad liberal, que tiene sólo los segundos. Puesto que el propietario tiene obligaciones en relación con su cosa, no puede hacer o dejar de hacer lo que le plazca, puesto que está obligado a hacerla productiva. Así, la riqueza controlada por los propietarios debe ser puesta al servicio de la comunidad a través de su explotación económica ${ }^{12}$. Por consiguiente, el Estado sólo está obligado a proteger la propiedad en tanto y en cuanto ésta cumpla con tal función social ${ }^{13}$. Esta concepción ha recibido algunas críticas ${ }^{14}$, y se apoya en una descripción de los seres humanos emplazada sobre la solidaridad, diferente a la concepción liberal individualista sostenida desde la modernidad ${ }^{15}$.

En "Duguit, ¿y después? Derecho, propiedad y relaciones sociales" ", Thomas Boccon Gibod propone una relectura actual de los aportes teóricos de León Duguit en torno a la propiedad, a la que concibe como una relación entre personas -una relación social-, antes que una relación de los hombres con las cosas. En esta relación social el derecho que se tiene sobre las cosas se encuentra asociado al "poder de hecho" que se tiene sobre las personas, en virtud de tal derecho. Introduce así el

12 Ídem.

13 Sobre el tratamiento constitucional de la función social de la propiedad en Argentina, ver ETCHICHURY, Horacio J., "La función social de la propiedad en la Constitución argentina: Tres momentos del siglo XX", en Revista de Historia Constitucional, № 20, 2019. Disponible en: http://www.historiaconstitucional.com, pp. 1021-1042 (accedido el 09/04/2020).

14 Para un abordaje de las aporías y tensiones en el pensamiento de Duguit en clave historiográfica, ver PASQUALE, Florencia, "La función social de la propiedad en la obra de León Duguit: Una re-lectura desde la perspectiva historiográfica", en Revista de Historia Constitucional, № 15, 2014. Disponible en: http://www.historiaconstitucional.com, pp. 93111 (accedido el 08/04/2020).

15 "Para Duguit, esta forma de concebir al sujeto y la sociedad pierde de vista que la interdependencia entre las personas (que no es otra cosa que la solidaridad) es el elemento central de la realidad social. La solidaridad no es un principio político: es un hecho social". FOSTER, Sheila y BONILLA MALDONADO, Daniel, op. cit., p. 14.

16 Publicado como "Duguit, et après? Droit, propriété et rapports sociaux" en Revue Internationale de Droit Économique, 2014/3 t. XXVIII, pp. 285 a 300. Disponible on line desde el 19 de febrero de 2015, consultado por última vez el 8-V-2020. URL: https://www.cairn.info/ revue-internationale-de-droit-economique-2014-3-page-285.htm. 
fenómeno del poder para el análisis de la relación social que define a la propiedad, la que estaría determinada por cierto tipo de relación entre las personas. Por lo tanto, la modificación de la propiedad exigiría en primer lugar modificar estas relaciones interpersonales, para abordar luego el segundo aspecto implicado, la relación de una persona con las cosas.

Sin eludir el abordaje de las limitaciones y dificultades en las ideas de Duguit, el trabajo rescata la actualidad de tales ideas para reflexionar críticamente sobre la relación entre propiedad privada y libertad individual. A tal efecto, recorre los fundamentos de la propiedad como función social, abordando luego las tensiones e interpretaciones posibles en la teoría duguista, donde se detiene en la noción de valor, no como propiedad intrínseca de un bien -que determina su apropiación individual-, sino como el resultado de un proceso social, donde las intervención de las instituciones públicas puede jugar un rol decisivo. Así, a partir de la propiedad como función social infiere el análisis de los procesos sociales por los que un bien es reconocido como susceptible de apropiación e intercambio en el mercado.

Creemos que la intuición de Duguit de considerar las relaciones de propiedad desde el prisma de las relaciones de poder encierra un gran potencial, que ofrece múltiples direcciones de desarrollo, y resulta de utilidad para el análisis de muchos fenómenos políticos, económicos y culturales que se dan en la Argentina actual. Con todo, el trabajo de Boccon Gibod constituye un aporte valioso e interesante para abonar las reflexiones en torno a la propiedad privada en sociedades desigualitarias, como la nuestra, donde existen millones de personas para quienes lo privado no equivale sino a privación de bienes básicos para una existencia digna.

\section{Bibliografía}

Arendt, Hannah (2012) La condición humana. Editorial Paidós, Buenos Aires. 
Beccaria, Cesare (2015) Tratado de los delitos y de las penas. Editorial Universidad Carlos III de Madrid.

Boccon, Thomas (2014) "Duguit, et après? Droit, propriété et rapports sociaux" en Revue Internationale de Droit Économique, $\mathrm{N}^{\circ}$ 28. En línea en: https://www.cairn.info/revue-internationale-de-droit-economique-2014-3-page-285.htm

Castel, Robert y Haroche, Claudine (2003) Propiedad privada, propiedad social, propiedad de sí mismo. Editorial Homo Sapiens, Rosario.

Chaparro Medina, Paola y Bustos García, Brenda (2018) "El dispositivo de excepción en las sociedades contemporáneas: apuntes para reflexionar en torno al cuerpo femenino", en RELACES, $N^{\circ}$ 26, Año 10. En línea en: www.relaces.com.ar

Etchichury Horacio (2019) "La función social de la propiedad en la Constitución argentina: Tres momentos del siglo XX", en Revista de Historia Constitucional, $\mathrm{N}^{\mathrm{o}}$ 20. En línea en: http:// www.historiaconstitucional.com

Foster, Sheila y Bonilla Maldonado, Daniel (2013) "Introducción. La función social de la propiedad en perspectiva comparada" en La función social de la propiedad. Editorial Eudeba, Buenos Aires.

Fittousi, Jean-Paul y Rosanvallon, Pierre (2003) La nueva era de las desigualdades. Editorial Manantial, Buenos Aires.

Locke, John (2005) Ensayo sobre el gobierno civil. Editorial Gradifco. Buenos Aires.

Pasquale Florencia (2014) "La función social de la propiedad en la obra de León Duguit: Una re-lectura desde la perspectiva historiográfica", en Revista de Historia Constitucional, $\mathrm{N}^{\mathrm{o}} 15$, 2014. En línea en: http://www.historiaconstitucional.com

Rabotnikof Nora (2008) "Lo público hoy: lugares, lógicas y expectativas", en Iconos, $\mathrm{N}^{\circ}$ 32, Flacso-Ecuador, Quito.

Russel, Bertrand (1978) Principios de reconstrucción social. Editorial Espasa-Calpe, Madrid 